\title{
Convulsions after the administration of high dose ropivacaine following an interscalenic block
}

To the Editor:

We report the unintentional administration of $400 \mathrm{mg}$ ropivacaine during an interscalenic block in a patient suffering from hemolytic-uremic syndrome and epilepsy. The patient was scheduled for the creation of an arterio-venous fistula of the left forearm.

The interscalenic block was performed with a neurostimulator and $400 \mathrm{mg}$ ropivacaine $\left(6.15 \mathrm{mg} \cdot \mathrm{kg}^{-1}\right)$, instead of the intended $200 \mathrm{mg}$, were injected incrementally over ten minutes. Twenty minutes after the end of injection, the patient presented generalised convulsions, which were treated with intravenous thiopental. The total venous ropivacaine concentration measured one hour after the block was $2.09 \mathrm{mg} \cdot \mathrm{l}^{-1}$.

Although a partial intravascular injection of ropivacaine cannot be excluded, the casual relationship between the block and the seizure remains uncertain. The large dose mistakenly injected is a good explanation; however the ropivacaine concentration measured here is in the same range as in other studies where no such toxicity was demonstrated. ${ }^{1,2}$ One explanation is that seizure thresholds for local anesthetics in epileptic patients are modified. Moreover, the higher levels of plasmatic alpha-1-acid glycoprotein, inherent to chronic renal failure, may have prevented more serious complications in this case.

This unintentional injection of a large dose of ropivacaine illustrates its high cardiovascular safety. ${ }^{3}$

C. Mardirosoff $\mathrm{MD}$

Lionel Dumont MD

Annemasse, France

\section{References}

I Hickey R, Blanchard J, Hoffman J, Sjovall J,

Ramamurthy $S$. Plasma concentrations of ropivacaine given with or without epinephrine for brachial plexus block. Can J Anaesth 1990; 37: 878-82.

2 Knudsen K, Sunrküla MB, Blomberg S, Sjövall J, Edvardsson $N$. Central nervous and cardiovascular effects of i.v. infusions of ropivacaine, bupivacaine and placebo in volunteers. Br J Anaesth 1997; 78: 507-14.

3 Ala-Kokko TI, Löppönen A, Alabubta S. Two instances of central nervous system toxicity in the same patient following repeated ropivacaine-induced brachial plexus block. Acta Anaesthesiol Scand 2000; 44: 623-6. 